Sultan Qaboos University Journal of Arts \& Social Sciences
جامعة السلطان قابوس

مجلة الآداب والعلوم الاجتماعية

\title{
The Social Impact of Social Networking Media on Teenagers From 13 to 19 Years Old in Oman
}

Yousuf Salim AlHinai

Assistant Professor

Department of Information Systems College of Economics and Political Science Sultan Qaboos University yalhinai@squ.edu.om
Juhaina Alsabahi and Zahra AlWahaibi

Department of Information Systems College of Economics and Political Science Sultan Qaboos University 


\title{
Investigatng The Social Impact of Social Networking Media on Teenagers From 13 to 19 Years Old in Oman
}

\author{
Yousuf Salim AlHinai, Juhaina Alsabahi and Zahra AlWahaibi
}

\section{Abstract}

The burst in the use of social networking sites such as MySpace, Facebook, Bebo and Friendster has brought many opportunities, changes and challenges into our world. The impact of this type of media can be social, psychological, and/or economic. For many societies, the social impact is a major concern since these technologies with their rapid spread have succeeded in influencing the attitudes of various groups of individuals. The role that social media played in the recent unrests in the Arab world is a clear example of such an impact. Oman, like all other countries, is also facing the same challenge. Among all other age groups in Oman, teenagers from 13 to 19 years old make up a major segment in the demographic structure of the country. Therefore, it is very important to study and understand the impact of the rapidly-growing social networking media on this group. The present research aims to contribute to this understanding by investigating the social impact of social networking media on teenagers in Oman. We survey teenagers' use of and perceptions about these technologies, in addition to parents' perceptions. By combining these two perspectives, this research aims to provide several contributions to both theory and practice. The results revealed that almost all teenagers $(99 \%)$ agreed that the social networking sites are beneficial. They believe that using social networking sites does not impact their social behavior.

Keywords: Social Networking Media, Social Impact, Teenagers, Parents, Oman

\section{تأثير شبكات التواصل الاجتماعي على المراهقين (با-19 سنة) في سلطنة عمان}

\author{
يوسف سالم الهنائي، جهينة الصباحي و زهرة الوهيبي
}

\begin{abstract}
وفر الاستخدام الهائل لمواقع التواصل الاجتماعي مثل Myspace و Facebook و Bebo و Friendster الكثير من الفرص والتح والتحولات

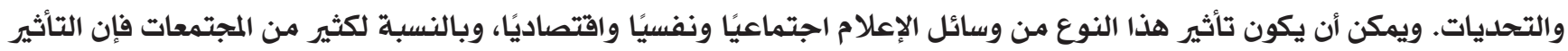

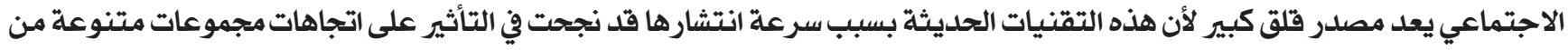

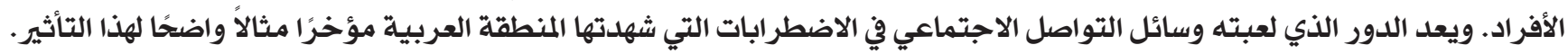

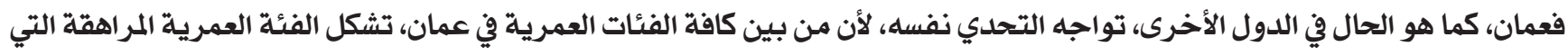

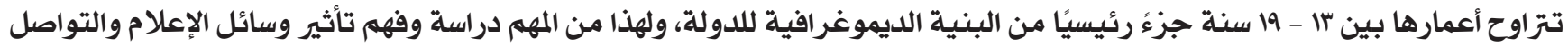

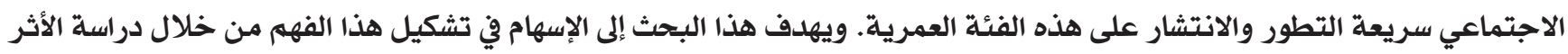

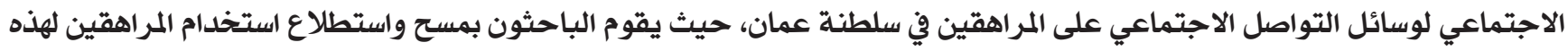

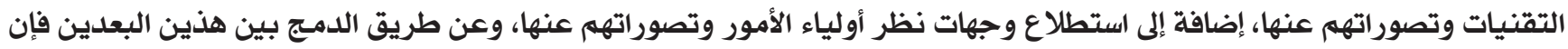

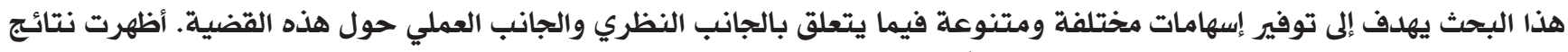

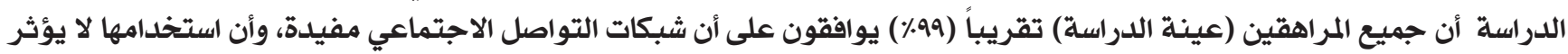
على سلوكهم الاجتماعي.
\end{abstract}




\section{Introduction}

The growth of social networking technology has been exponential in the past few years. Social networking sites such as Facebook, MySpace, Twitter have attracted millions of users who incorporated the use of this technology as part of their normal daily routine (Ofcom,2008;Young, 2013). Social networking sites focus on building social relations among people by allowing them to share information, photos or videos, share interests and activities, use blogging to express their views and so on (Boyd \& Ellison, 2008). Social networking sites allow users to create personal profile pages in which they can express their ideas and views and also add friends to their lists (Sunden, 2003; Christine \& Girish, 2012). Moreover, some sites allow users to enhance their profiles by adding multimedia content or modifying their profile's look and feel while others, such as Facebook, allow users to add applications that allow them to accomplish additional useful tasks (Boyd \& Ellison, 2008). Once you are granted access to a social networking site you can begin to socialize by reading the profile pages of others and possibly contacting them and start a new friendship.

There are several social networking sites that users can choose from based on their preferences. For example, about 63 per cent of children are more likely to use Bebo, while 62 per cent of adults are most likely having a Facebook profile (Ofcom, 2008; Christine \& Girish, 2012). In addition, 42 per cent of teenagers are using social networking sites like MySpace or Facebook (Lenhart \& Madden, 2007). A study by Joseph and Califano (2011) found that 70 per cent of teenagers usually spend most of their time on social networking sites compared to 30 per cent of teenagers who do not (Joseph \& Califano, 2011). This high percentage of daily time spent by teenagers on social networking sites is very likely to affect them in different ways.

Social networking can impact users physically, psychologically, attitudinally, and/or socially. For example, research found that teenagers who use social networking sites are more likely to get drunk, use drugs and do risky behaviors (Califano, 2011). Compared to other teenagers, teenagers who are heavy users of social networking sites are three times likely to drink alcohol, four times probable to smoke, and three to four times more able to obtain marijuana and illegal prescription drugs (Califano, 2011). Social networking sites allow users to communicate in multiple ways with many people who have different thoughts and background. This interaction is the foundation of changing the behavior and attitudes of individuals within a social system (DiMaggio, Hargittai, Neuman, \& Robinson, 2001; Cunliffe, Morris, Prys C. 2013).

A study by Lenhart (2005) showed that over 21 million teenagers have access to and actively used the internet on a regular basis. Teenagers routinely interact with one another through social networking sites, 85 per cent of teenagers are reported to do this on a daily basis and in activities, browsing and searching was the first activity, with over 80 per cent of both teenagers and adults having planned to do so that day (Hughes, 2006; Donner J. and Walton M., 2013). Though some technologies such as MySpeace were originally targeted at a user group aged 20+, Information Technology has immense popularity among teenagers ( Lipsman \& Odum, 2006 ). According to Howe (2006), MySpace traffic grew by $367 \%$ between 2005 and 2006, making it the number one social networking site. Furthermore, it boasts the highest retention rate with $67 \%$ of visitors returning (Howe, 2006).

It seems that the growth of the use of social networking media is far from slowing down. Statistics by Salem and Mourtada (2012) show that by March 2012, there were at least 1,311,882 active Twitter users and more than 43 million users of Facebook in the Arab world. In Oman, the number of active Twitter users exceeded 6,550 in March 2012 with more than half a million Tweets during that month alone. From September 2011 to March 2012, the number of Twitter users in Oman increased by 92.19 per cent $(3,142$ users more). Following the same growth trend, the number of Facebook users in Oman was almost 500,000 by May 2012. In only 8 months from September 2011 to May 2012, the number of Facebook users in Oman grew by 50.21 per cent, that is, 154 thousand users more. Looking into the future, Facebook users in Oman are expected to increase by 14.81 per cent every year, while Twitter users will increase by 0.23 per cent annually.

This dramatic growth in the use of social networking media will bring with it several influences on the social system in Oman. Therefore, this paper aims to explore this issue by answering the following question: What is the social impact of social networking on teenagers in Oman?

The focus on teenagers (from 13-19 years old) is based on the demographical structure in Oman which shows that the Omani society is a young social system. Therefore, by focusing on teenagers, 
we hope to inform about the social impact that these technologies have on the Omani society. The study involves a triangulation of methods. We use quantitative questionnaires to examine teenagers' and parents' perspectives on the topic.

\section{Litearture review}

The growth of Internet use and the recent developments in the telecommunications industry has brought many changes and challenges to societies (Ofcom, 2008; Bernard \& Walter, 2012). Nowadays, wireless internet enabled people to use the internet and communicate with each other wherever they are whenever they want. One of the most noticeable developments is the dramatic use of social networking media.

Social network sites are web-based services that allow individuals to construct a public or semi-public profile within a bounded system, articulate a list of other users with whom they share a connection, and view and traverse their list of connections and those made by others within the system (Boyd \& Ellison, 2007; Young, 2013). Social networking sites such as, Facebook, Twitter, Myspace have attracted millions of users around the world. Figure1 below shows the evolution of the most famous social networking sites over the years (Boyd \& Ellison, 2007; Young, 2013).

As the number of sites grew, they have diversified in terms of focus. According to Boyd \& Ellison (2007) and Young (2013), alongside more general sites such as MySpace, Bebo and Facebook, other niche sites have sprung up. Examples include Linkedln, which was founded in 2003 and is based on developing business and employment networks, and Flickr, which is specialised in photo-sharing. In October 2007 Saga announced that it was launching Sagazone, a social networking site aimed exclusively at the over50s (Boyd \& Ellison, 2007). Among others, Facebook witnessed the most dramatic growth around the world due to its practicality (Livingston, 2008; Christine \& Girish, 2012). Myspace site is the girls' preferred networking site because of its distinguished design features which allow the users to design their own background (Livingston, 2008).

According to Arab social Media Report (2011), the total number of Facebook users in the Arab world stands at 27,711,503 as of April 5, 2011 compared to $21,377,282$ users in January 5,2011 . This number had almost doubled since April 2010 increasing from 14,791,972 users. The Gulf Council Countries (GCC) occupy the top five Arab Facebook users as a percentage of population, with Lebanon being the only exception. In Oman, there are more than 500,000 Facebook users. The number of Tweets sent by Twitter users in Oman exceeds 500,000 every month. Facebook users in Oman are expected to increase by 14.81 per cent every year, and similarly, Twitter users will increase by 0.23 per cent annually.

With the increasing accessibility of social networking sites using wireless internet and mobile devices it became easier and faster for users to create a profile and join social networking sites and start making friends (Ofcom, 2008; Young, 2013). While different social networking sites differ in their look and feel and general features, the underlying concept is allowing users to create a profile to identify themselves and then link to list of friends who are also users of the same site (Sunde'n, 2003). Profiles are unique pages where one can type oneself into being, in which an individual is asked to fill out forms containing a series of questions. The profile is generated using the answers to these questions, which typically include descriptors such as age, location, interests, and an about-me sections with the option to add profile photos, multimedia and many other futures (Sunde'n, 2003; Christine \& Girish, 2012). With such ease of use and wide range of features, social networking sites quickly became a global meeting point in which individuals can get exposed to a wide variety of issues, cultures, information and individuals.

The wide usage of technology such as the Internet can bring many educational and self-development opportunities to users especially young individuals (Turow, 1999; Donner \& Walton, 2013). For young users, these technologies open a new world of knowledge and information. However, it is also argued that such a virtual space could deviate young users, especially teenagers, from the learning of ethical behaviors in real life (Davis, 1976). According to Ofcom research, almost half (49\%) of children aged 8-

Table (1): Simplified timeline of selected social networking sites (2000-2007)

\begin{tabular}{|c|c|c|c|c|c|c|c|}
\hline 2000 & 2001 & 2002 & 2003 & 2004 & 2005 & 2006 & 2007 \\
\hline Friends Reunited & Wikipedia & Friendster & Linkedln, MySpace, Hi5 & $\begin{array}{c}\text { Flicker, Piczo ,Facebook } \\
\text { (Harvard only) }\end{array}$ & $\begin{array}{c}\text { Bebo, Facebook } \\
\text { (school networks), } \\
\text { Youtube }\end{array}$ & $\begin{array}{c}\text { Facebook } \\
\text { (everyone), } \\
\text { Twitter }\end{array}$ & Sagazone \\
\hline
\end{tabular}


17 who use the internet have set up their own profile on a social networking site (Ofcom, 2008). Also, most of Facebook users are younger students aged 18-22 (Christine \& Girish, 2012). This higher percentage of teenagers using virtual space can bring many changes to the traditional source of learning of information as well as behaviours such as homes and schools. Nowadays, teenagers live in an extended youth. They become dependent in term of education and economics but independent in term of consumption and spending their free time (Gadlin, 1978).

These challenges become more critical when one knows that most users of social networking media are teenagers. According to BBC News about 31\% of MySpace users are under 18 years, as are $54 \%$ of Bebo users in the USA (BBC News, 2006). Also, 6.6 million unique users aged 12-17 visited MySpace in August 2006 across Europe (Comscore, 2006). The Arab region is demographically a youthful one, where youth between the ages of 15 and 29 make up around one-third of the population (Arab social Media Report, 2011). In the Arab region also, teenagers make up a large portion of the user of social networking media. There are several reasons behind the popularity of social networking among teenagers. For example, the ability to connect with others easily is one of the most important reasons. According to Lennart \& Madden (2007), the authors found that $91 \%$ of teenagers use social networking to stay in touch with close friends while $82 \%$ stay in touch with friends who live in other places. Seventy two per cent use these sites to make plans with their friends and $49 \%$ use the sites to make new friends via these plans. Also, this study showed that $17 \%$ of teenagers use social networking to flirt and girls are more likely to use social networking sites to build friendships and boys to find new friends (Lenhart \& Madden, 2007). Moreover, girls are more likely than boys ( $37 \%$ vs. $23 \%$ ) to be friends with their coaches and teachers and also girls who use Facebook are substantially more likely than boys to have a private profile (70\% vs. $50 \%$ ) (Madden M., Lenhart A., Cortesi S., Gasser U., Duggan M., Smith A. \& Beaton M., 2013).

In addition, the flexibility of using social networking sites at any time encourages teenagers to join and spend a lot of time using them (Livingston, 2008). Furthermore, social networking sites give teenagers the opportunity to express themselves with almost no limits. Unlike traditional media such as newspapers social networking sites allow teenagers to express about their daily lives. Teenagers can communicate with people who have the same interest. This gives them a chance to meet people and make new friends, even when friendships are very doubtful. In short, teenagers like to have more ways to express themselves without fear of prejudice, and social networking sites give them just that (Akanksha, 2008; Young, 2013).

Through this fast growth and unlimited features, social networking sites open to teenagers wide horizons of virtual expression, freedom and connectivity. Yet these same features can also bring many social challenges for the society, parents and teenagers themselves. The study of the fast growth of social networking use among teenagers and the social impact this technology brings to teenagers' lives is important for many reasons. Firstly, social networking is unique because it combines both different methods of communication and different kinds of content (chats, video, visual images, audio) which gives this technology a distinctive entity compared to traditional technologies. Secondly, the examination of behavioural assumptions as a foundation of teenagers' choices can provide interesting insight on how people interact with social networking sites (DiMaggio, Hargittai, Neuman, \& Robinson, 2001). Thirdly, research in this area provides an opportunity for researchers to test theories of technology flow and effects of media which can help improve our understanding of these theories (DiMaggio, Hargittai, Neuman, \& Robinson, 2001). Our research aims to contribute to this understanding by assessing the social impact of social networking media on teenagers (from 13 to 19 years old) in Oman.

\section{Research design and methods}

To achieve the objectives, this research involved three data collection methods. First, a quantitative questionnaire targeting 125 teenagers from 13-19 years old in various schools, universities, and colleges in Oman. Second, a quantitative questionnaire targeting 100 parents who have teenaged children. Thirdly, a qualitative face-to-face survey of four social workers who are experts in teenager psychology. For the teenagers survey eight schools were targeted, four in the Capital of Muscat and the other four are from different regions. The parents of these teenagers were surveyed in the parents questionnaire. For the social workers survey, experts from Sultan Qaboos University as well as social workers in schools were interviewed. 


\section{Findings}

The sample in the questionnaire involved 125 teenagers who are between 13 and 19 years old. The findings show that most of the teenagers (about 85\%) are using social networking sites. In comparison, only $15 \%$ of teenagers indicated that they did not join social networking sites. Moreover, most of the sample showed that they have self-interest in using several social networking sites. As Figure 1 below shows, the majority of the teenagers have a Facebook account (86\%) while half of the samples are users of general forums such as Sablat Oman, Noor Oman and Rooh Oman. The findings also show that on average, most teenagers spend about 3 to 6 hours a day in using social networking sites. Only a small group of the sample spend less than 3 to 6 hours a day or twice a week.

Teenagers who do not use social networking sites said that these sites are not interesting to them and/ or they do not have free time to spend on the sites. Also, some females indicated that their parents are again using social networking sites and therefore they do not use them. On the other hand, teenagers who use social networking indicated that the main reason for using is the ability to chat with family and friends using these sites.

In terms of the purpose of using social networking sites, $29 \%$ of teenagers use them for chatting with family and friends, $27 \%$ for entertainment, $19.4 \%$ for finding information, as Figure 2 shows. The rest use the sites for education, business and other purposes. In addition, Most of teenagers are using social networking sites in different places. It doesn't matter to them if other people are around. A few teenagers indicated, however, that they like to use social networking sites alone in a private setting. Furthermore, the friend list of teenagers accounts in social networking sites generally includes friends, colleagues, family and school mates.

\section{Benefits of social networking sites}

Almost all teenagers (99\% of the sample) agreed that the social networking sites are beneficial. For example, they find these sites useful for finding new friends (18\%), communicating with others with similar interests and tastes (21\%), sharing information (20\%) and keeping up-to-date with news very quickly (18\%). On the other hand, teenagers who indicated that social networking sites are useless believe that using these sites means wasting their time and that online friends are not truthful and/or trustworthy.

\section{General impact on teenagers' behaviour}

In our study, we found that most teenagers believe that using social networking sites does not impact their social behaviour. They emphasized that the change is neutral, neither positive nor negative. In the study we chose some specific behaviours that might be affected by the use of social networking sites including self-esteem, dependency, discipline, attention and

Figure (1): Teenagers' use of various social networking media

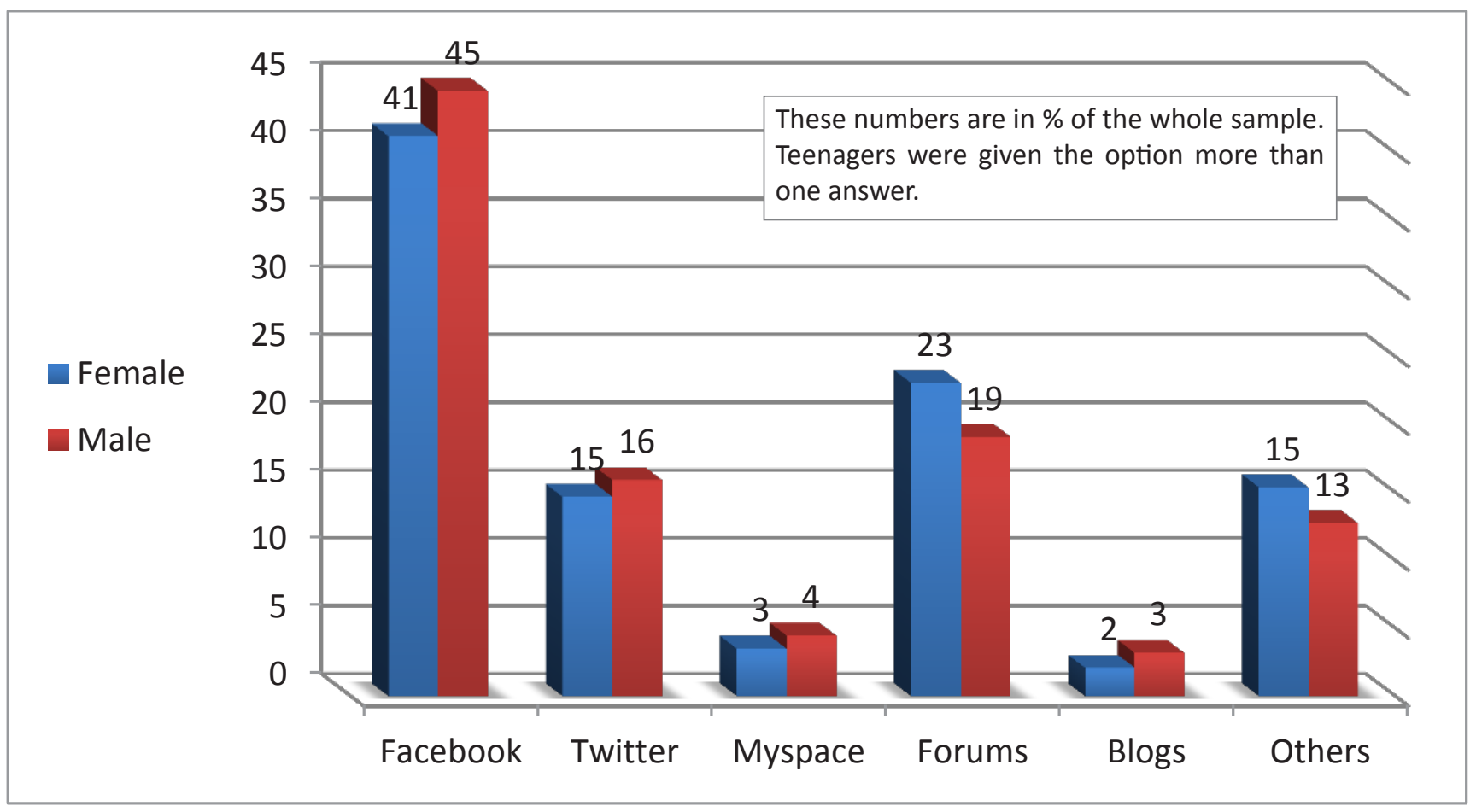


risk taking. Interestingly, the findings indicate that these behaviours are not directly affected by use of social networking. However, teenagers agreed that confidence and motivation specifically are generally affected by the use of this technology. Table 1 and Table 2 below show these results for male and female teenagers.

\section{Parents' Survey}

In this part of the study, the general opinions and perceptions of 100 parents were studied. Generally, as Figure 3 shows below, most parent nowadays actively use social networking sites with the majority using (more than 50\%) forums and Facebook while a few use blogs. The findings also show that the majority of parents have no objection about their teenager children having an account on social networking sites because most of them trust their children. In addition, most parents use social networking sites and therefore feel that it's safe for their children to also use.

In addition, as Figure 3 depicts, majority of parents think that the most critical negative impact of using social networking sites by their teenager children include communicating with unapproved (bad) people $(36.06 \%)$, destroying or breaking teenager's relationship with other family members (26.23\%), isolation and loss of communication ability with others (23\%), and destroying teenagers own culture $(9.83 \%)$. This shows that while parents are not completely against their children's use of social media, they are still mostly concerned about the intrusion of others into the family and culture systems they have raised their children according to. This could be due to nature of the protective culture of the Omani society in general.

Table (2): Impact of social networking on male teenagers

\begin{tabular}{|c|c|c|c|c|c|}
\hline Behaviours & $\begin{array}{c}\text { Strongly } \\
\text { Agree }\end{array}$ & Agree & Neutral & Disagree & $\begin{array}{l}\text { Strongly } \\
\text { disagree }\end{array}$ \\
\hline Self-esteem: loving and feelings about one's self & $8.60 \%$ & $31.88 \%$ & $40.58 \%$ & $14.50 \%$ & $4.35 \%$ \\
\hline Confidence: belief in one's self and abilities & $31.88 \%$ & $31.88 \%$ & $18.84 \%$ & $13 \%$ & $4.35 \%$ \\
\hline Dependency: rely on others & 0 & $27.54 \%$ & $47.83 \%$ & $15.94 \%$ & $8.50 \%$ \\
\hline Discipline: follow rules & $23.19 \%$ & $27.54 \%$ & $39.13 \%$ & $5.80 \%$ & $4.35 \%$ \\
\hline Attention: mental focus & $29 \%$ & $26.10 \%$ & $27.54 \%$ & $17.40 \%$ & 0 \\
\hline Motivation: desire, interest or drive to accomplish & $8.70 \%$ & $52.17 \%$ & $30.43 \%$ & $8.70 \%$ & 0 \\
\hline Risk taking: taking actions with (expected) unpleasant or undesirable results & $7.25 \%$ & $23.90 \%$ & $47.82 \%$ & $16 \%$ & $1.45 \%$ \\
\hline
\end{tabular}

Table (3): Impact of social networking on female teenagers

\begin{tabular}{|c|c|c|c|c|c|}
\hline Behaviours & Strongly Agree & Agree & Neutral & Disagree & Strongly disagree \\
\hline Self-esteem: loving and feelings about one's self & $18 \%$ & $26 \%$ & $38 \%$ & $15 \%$ & $4 \%$ \\
\hline Confidence: belief in one's self and abilities & $29 \%$ & $42 \%$ & $14 \%$ & $13 \%$ & $3 \%$ \\
\hline Dependency: rely on others & $5 \%$ & $9 \%$ & $28 \%$ & $34 \%$ & $14 \%$ \\
\hline Discipline: follow rules & $12 \%$ & $22 \%$ & $51 \%$ & $14 \%$ & $2 \%$ \\
\hline Attention: mental focus & $19 \%$ & $28 \%$ & $50 \%$ & $11 \%$ & $2 \%$ \\
\hline Motivation: desire, interest or drive to accomplish & $20 \%$ & $30 \%$ & $33 \%$ & $15 \%$ & $0 \%$ \\
\hline $\begin{array}{l}\text { Risk taking: taking actions with (expected) unpleas- } \\
\text { ant or undesirable results }\end{array}$ & $6 \%$ & $27 \%$ & $29 \%$ & $14 \%$ & $18 \%$ \\
\hline
\end{tabular}




\section{Conclusion}

Social networking sites are great tools to communicate and they will not spread very widely unless there are clear benefits to the users. In this study, we aimed to explore the impact of these sites on social behaviours and attitudes of teenagers in Oman. In contrast to our initial expectations before undertaking this study, the findings show that social networking sites actually have a positive social impact on teenagers. This conclusion is supported by the results of both teenagers and parents surveys. The general impression is that teenagers should be allowed to use social networking sites but with conditions set by their parents or guardians. One of the most important recommendations to achieve this balance between allowing the use and preventing harm on teenagers is that parents should be friends with teenagers and educate them on how to use social networking sites responsibly. Teenagers must feel secure and live in a friendly environment in order to increase their level of self-monitoring and self-discipline.

Figure (2): Purpose of using social networking sites

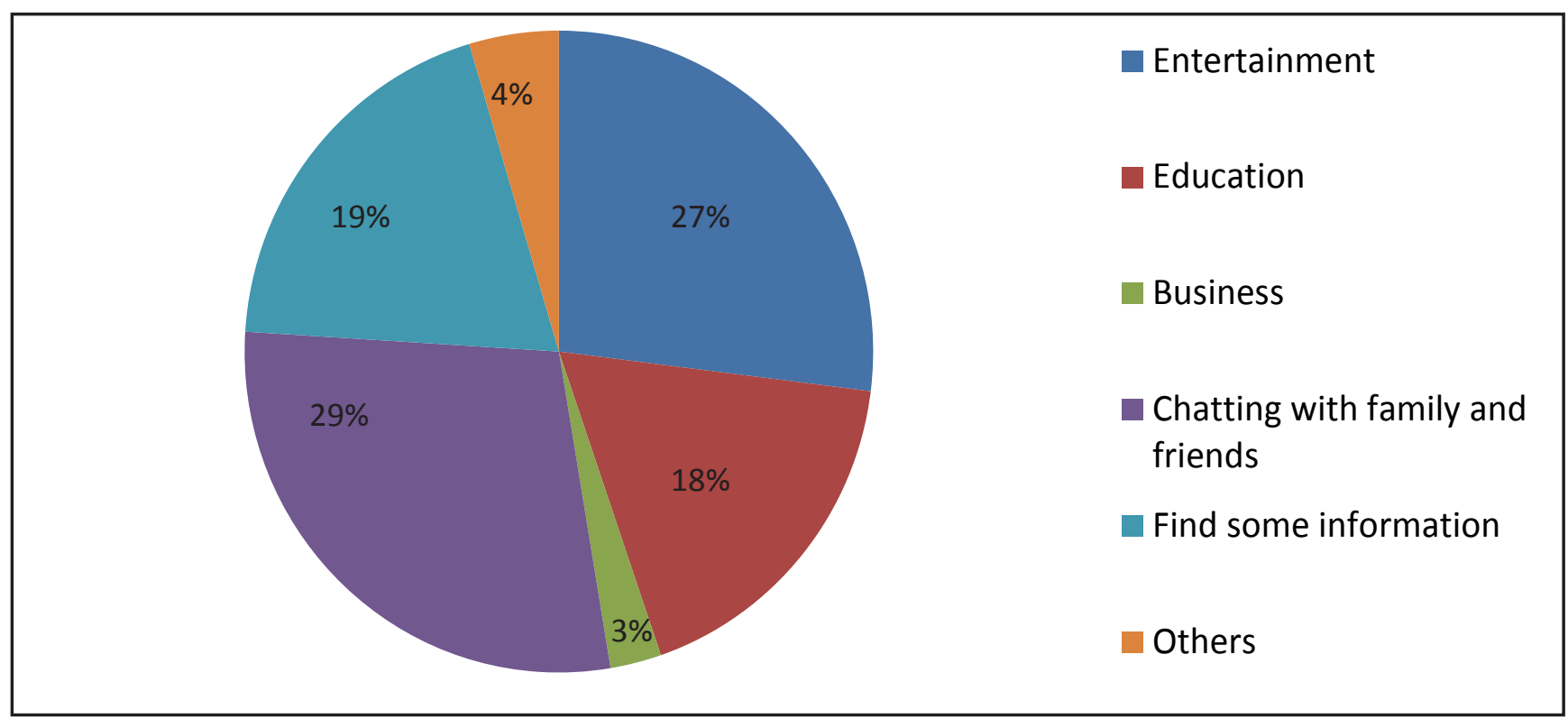

Figure (3): Parent's perceptions of the negative impact of social networking on teenagers

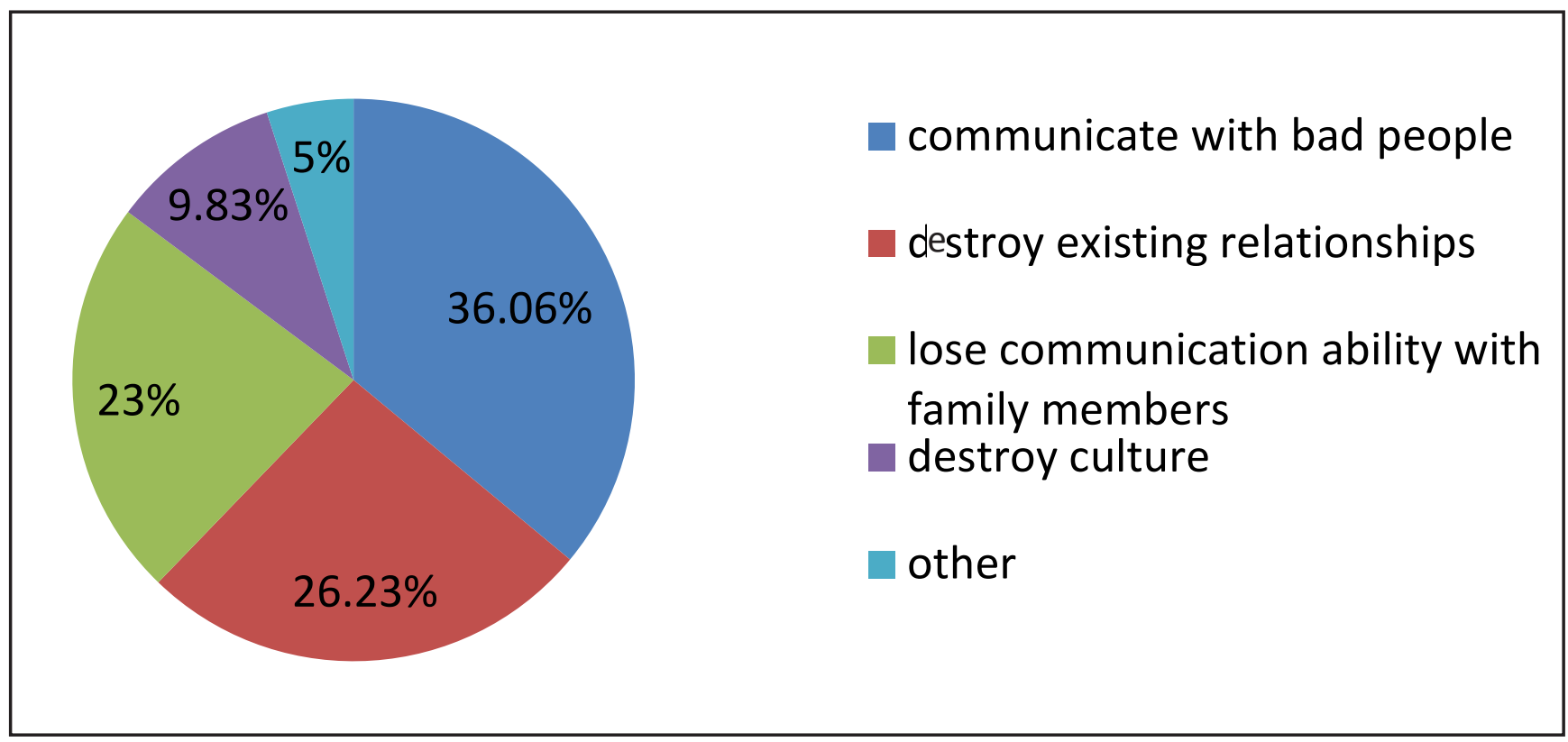


Gander:

\section{Appendices}

Male

$\square$ Female

Age:

$\square 13$

$\square 14$

$\square 15$

$\square 16$

17

$\square 18$

$\square 19$

Objective: To see the number of teenager users of social networking in Oman and the approximate hours they spend in using it.

Do you have a social network account?

$\square$ Yes $\quad \square$ No

If Yes, which social website do you use? (you can choose more than one)

$\square$ Facebook $\square$ Twitter $\square$ Myspace

$\square$ Forums ( ex: Sablat Oman, Noor Oman, Roo7 Oman, Al madars, Educational forum)

Blogs (ex: Omani blog, maktoob blog, Omanizer blog)

$\square$ Others....(explain:

..)

If No, what is the main reason? (you can choose more than one)

$\square$ I don't have time.

$\square$ It is not interesting for me

$\square$ I don't want any publicity

It is against my religion

Others.....(explain:

How many hours do you spend in social networking sites?

$\square$ More than 6 hours a day

$\square$ From 3- 6 hours a day

$\square$ Less than 3 hours a day

$\square$ Twice a week

$\square$ Others....(explain:

Objective: The reasons or the most common reason for using social networking sites and the importance of these sites.

What do social networking sites offer you? (you can choose more than one)

$\square$ Entertainment

Education

Business

$\square$ Chatting with family and friends

Find some information

Others....(explain: 
Where do you usually use social networking sites?

$\square$ Around the people

$\square$ Alone

$\square$ Doesn't matter

$\square$ Others....(explain: ..)

Who are in your friend list in the social networking sites? (you can choose more than one)

$\square$ Friends and colleges

$\square$ Family

$\square$ School mates

$\square$ Other....(explain: ...)

Objective: Effects of social networking on teenagers behaviors.

Do you feel that your behavior has changed ever since starting a social network account?
$\square$ Yes
$\square$ No
I don't know

If so, to what extent:

Extremely positively

$\square$ Positively

$\square$ Neutral

$\square$ Negatively

Extremely negatively

How much is using social networking sites affecting your behaviors?

\begin{tabular}{|l|l|l|l|l|l|}
\hline Behaviours & $\begin{array}{l}\text { Strongly } \\
\text { Agree }\end{array}$ & Agree & Neutral & Disagree & $\begin{array}{l}\text { Strongly } \\
\text { disagree }\end{array}$ \\
\hline Self-esteem: loving and feeling about yourself & & & & \\
\hline Confidence: belief in yourself and your abilities & & & \\
\hline Dependency: relies on others & & & \\
\hline $\begin{array}{l}\text { Discipline: act with rules } \\
\text { Attention: act of attending, especially by direct- }\end{array}$ & & & \\
\hline ing the mind to an object & & & & \\
\hline Motivation: desire to do, interest or drive & & & & \\
\hline $\begin{array}{l}\text { Risk taking: taking actions which might have } \\
\text { unpleasant or undesirable results }\end{array}$ & & & & \\
\hline
\end{tabular}


Objective: The benefit of social networking.

Do you think social networking sites are beneficial?
$\square$ Yes
$\square$ No
I don't know

If Yes, what are the benefits? (you can choose more than one)

$\square$ Find new friends

$\square$ communicate with others

$\square$ share information

$\square$ Keep up-to-date on news more quickly

$\square$ Make friends with similar interests and likes

$\square$ Achieve a more personal connection

$\square$ Others....(explain: ...)

If No, why? (you can choose more than one)

$\square$ Because it is wasting time

$\square$ Because most new friends do not talk truly

$\square$ Because social networking sites are not interesting for me

$\square$ Because it is against my religion

$\square$ Others....(explain: ..)

\section{Parents Questionnaire:}

Objective: To see how parents care and pay attention to their children while using the social networking sites. Do you have an account in social networking sites?
Yes
$\square$ No

If Yes, which social website do you use: (you can choose more than one)

$\square$ Facebook $\square$ Twitter $\square$ Myspace

$\square$ Forums ( ex: Sablat Oman, Noor Oman, Roo7 Oman, Al madars, Educational forum)

Blogs (ex: Omani blog, maktoob blog, Omanizer blog)

$\square$ Others....(explain:

Does your son/daughter have a social network account?

$\square$ Yes $\quad \square$ No $\quad \square$ Idon't know

Do you agree that your son/daughter has a social network account?
$\square$ Yes
$\square$ No
$\square$ Doesn't matter

Why? (you can choose more than one)

$\square$ Because everybody has an account

Because I trust him/her 
Because it is against my religion

Because it is just an entertainment

Other....(explain:

Do you follow your child while they are using social networking sites?
$\square$ Yes
$\square$ No
$\square$ Doesn't matter

Objective: Effects of social networking on teenagers behaviors.

Do you think people abuse social networking communities?
$\square$ Yes
$\square$ No
I don't know

Why? (you can choose more than one)

$\square$ Because of disruption in families

$\square$ Because nobody talks to him/her at home

$\square$ Because of corrupting culture

$\square$ Because he/she may talk with bad people

$\square$ Other....(explain:

Do you think social networking is healthy? (Ex: physically or mentally)
Yes
No
I don't know

Objective: The reasons or the most common reason for using social networking sites.

In your opinion, why do teenagers these days join social networking groups? (you can choose more than one)

$\square$ Find new friends

Exploit his/her free time

$\square$ Chat with family and friends

$\square$ For entertainment

$\square$ For education

$\square$ For business

$\square$ Find some information

Others....(explain: )

Objective: The benefit of social networking.

In your opinion, are social networking sites beneficial?
$\square$ Yes
No
don't know

If yes, what are the benefits?

$\square$ Find new friends

Communicate with others

$\square$ Share information

$\square$ Keep up-to-date on news more quickly 
Make friends with similar interests and likes

Achieve a more personal connection

Others....(explain:

If No, why? (you can choose more than one)

Because it is wasting time

Because most new friends do not talk truly

Because social networking sites are not interesting for me

Because it is against my religion

Others....(explain: ...)

\section{References}

1. Acquisti, A., \& Gross, R. 2006. 'Imagined communities: Awareness, information sharing, And privacy on the Facebook'. In P. Golle \& G. Danezis (Eds.), Proceedings of 6th Workshop On Privacy Enhancing Technologies (pp. 36-58). Cambridge, UK: Robinson College.

2. Akasha, 2006. The Effect of Social Networking on Teens, Social Media Agency, (pp.56). Arab Social Media Report, 2011, Dubai School of Government, Convention Tower, Level 13, P.O. Box 72229, Dubai, United Arab Emirates, Tel: 971-4-329-3290, Fax: 971-4-329-3291, Email: info@dsg.ac.ae, www. dsg.ae Arab www.ArabSocialMediaReport.com. , socialmedia@dsg.ac.ae

3. BBC News, 2006 'Social Sites Wrestle for Top Spot', 24 May, URL (consulted 26 November 2007): http:// news.bbc.co.uk/2/hi/technology/5012194.stm

4. Bernard B. \& Walter A. 2012. 'Factors Affecting the Provision of ICT Services in a Developing Economy: The Case of Ghana'. Published by: TORNIO

5. Boyd, D., \& Ellison, N. 2008. Social Network sites: Definition, History, and Scholarship. In International communication association, (pp. 211, Social network sites : A definition), journal of computer-Mediated Communication.

6. Boyd, D. and Ellison, N. 2007 'Social Network Sites: Definition, History, and Scholarship', Journal of Computer-Mediated Communication 13(1), URL consulted 30 January 2008 :http://jcmc.indiana. edu/vol13/issue1/boyd.ellison.html

7. Christine B. Williams and Girish J. 'Jeff' Gulati 2012 Bentley University, USA 'Social networks in political campaigns: Facebook and the congressional elections of 2006 and 2008'. Reprints and permission: sagepub.co.uk/journalsPermissions. nav . Published by: Sage

8. Comscore. 2006 'More than Half of MySpace Visitors Are Now Age 35 or Older', 5 October, URL (consulted 6 July 2007): http://www.comscore. com/press/release.asp?press_1019

9. Cunliffe D. , Morris D. , Prys C. 2013 UK. 'Young Bilinguals' Language Behaviour in Social Networking Sites: The Use of Welsh on Facebook'. Journal of Computer-Mediated Communication18 (c) International Communication Association.

10. Davis, R.E. Response to innovation: A study of popular argument about new mass media. New York: Arno Press, 1976. (Dissertation originally prepared in 1965.)

11. DiMaggio,P., Hargittai, E. ,Neuman, W.R.,\& Robinson, J., P., 2001. SOCIAL IMPLICATIONS OF THE INTERNET (pp.308). DiMAGGIO ET AL, Annu. Rev. Sociol. 2001. 27:307-36

12. Donner J. and Walton M. 2013. 'Your phone has internet - why are you at a library PC? Re-imagining public access in the mobile internet era'. Microsoft Research India, Lavelle Rd, Bangalore, India. The Centre for Film and Media Studies, University of Cape Town, Upper campus, Arts Block, Cape Town. www.springerlink.com

13. Gadlin, H. 1978 'Child Discipline and the Pursuit of Self: An Historical Interpretation', in H.W. Reese and L.P. Lipsitt (eds) Advances in Child Development and Behavior,Vol. 12, pp. 231-61. New York: Academic Press.

14. Howe, J. 2006. The hit factory. Wired. Available from: <http://wired.com/wired/archive/13.11/ 
myspace_pr.html> Retrieved 17.12.07.

15. Hughes, D. R. 2006. Recent statistics on internet dangers. Available from: <http://www.protectkids. com/dangers/stats.htm> Retrieved 17.12.07.

16. Joseph A. Califano, Jr., 2011, Teens and parents, National Center on Appointed Special Advocate Association.

17. Lenhart, A. and M. Madden, 2007. Social Networking Websites and Teens: an Overview, URL (consulted 20 December 2007): http://www. pewinternet.org/pdfs/PIP_SNS_Data_Memo_ Jan_2007.pdf

18. Lenhart, A. 2005. Protecting teens on the internet. Pew Internet and American life project. Available from: <http://www.pewinternet.org/PPF/r/36/ presentation_display.asp> Retrieved 17.12.07.

19. Lipsman, A. 2006. Comscore press release. Available from: <http://www.comscore.com/ press/release.asp?id=1019> Retrieved 17.12.07

20. Livingstone, S., 2008. New Media \& Society: Taking risky opportunities in youthful content creation: teenagers' use of social networking sites for intimacy, privacy and self-expression, (pp. 394,395, 396, 401). Published by: Sage.

21. Madden M., Lenhart A., Cortesi S., Gasser U., Duggan M., Smith A. and Beaton M. (2013). Teens, Social Media, and Privacy. Publish by: Pew Research Center's Internet \& American Life Project. http://pewinternet.org/Reports/2013/ Teens-Social-Media-And-Privacy.aspx

22. Ofcom, 2008. Office of communication: social networking a quantitative and qualitative research report into attitudes, behaviours and use,(pp.1, Introduction, Background), Published separately at: www.ofcom.org.uk

23. Odum, S. 2006. The dangers of MySpace.com for teens. CBN News. Available from: <http:// www.cbn.com/cbnnews/usnews/060510s.aspx> Retrieved 17.12.07

24. Silverstone, R. 2006. Domesticating Domestication: Reflections on the Life of aConcept, in T. Berker,M. Hartmann,Y. Punie and K. J. Ward (eds) The Domestication of Media and Technology, pp. 22948. Maidenhead: Open University Press.

25. Sundén, J. 2003. Material Virtualities: Approaching Online Textual Embodiment. New York: Peter Lang.

26. Turow, J. The Internet and the family: The view from parents, the view from the press. Philadelphia: Annenberg Public Policy Center, University of Pennsylvania, May 1999.

27. Young, K. (2013) Online and internet-based technologies: Social Networking, (PP 428, Introduction). Available from:http://books.google. com.om/books?hl=en\&lr=\&id=vZjCAQAAQBAJ\&oi =fnd\&pg=PA427\&dq=Online+and+internet-based+ technologies:+Social+Networking\&ots 